\title{
Geographic distribution and molecular analysis of porcine reproductive and respiratory syndrome viruses circulating in swine farms in the Republic of Korea between 2013 and 2016
}

Hyeonjeong Kang ${ }^{1,2}$, Ji Eun Yư ${ }^{1}$, Ji-Eun Shin ${ }^{1}$, Areum Kang ${ }^{3}$, Won-II Kim³ ${ }^{3}$ Changhee Lee ${ }^{2}$, Jienny Lee ${ }^{1}$, In-Soo Cho', Se-Eun Choe ${ }^{1}$ and Sang-Ho Cha ${ }^{1,4^{*}}$ (D)

\begin{abstract}
Background: Porcine reproductive and respiratory syndrome virus (PRRSV) causes devastating disease characterized by reproductive failure and respiratory problems in the swine industry. To understand the recent prevalence and genetic diversity of field PRRSVs in the Republic of Korea, open reading frames (ORFs) 5 and 7 of PRRSV field isolates from 631 PRRS-affected swine farms nationwide in 2013-2016 were analyzed along with 200 Korean field viruses isolated in 2003-2010, and 113 foreign field and vaccine strains.

Results: Korean swine farms were widely infected with PRRSVs of a single type (38.4 and 37.4\% for Type 1 and Type 2 PRRSV, respectively) or both types (24.2\%) with up to approximately $83 \%$ nucleotide sequence similarity to prototype PRRSVs (Lelystad or VR2332). Phylogenetic analysis based on the ORF5 nucleotide sequence revealed that Korean Type 1 field isolates were classified as subgroups $A, B$, and C under subtype 1, while Korean Type 2 field isolates were classified as lineages 1 and 5 as well as three Korean lineages (kor $A, B$, and C) with the highest infection prevalence in subgroup A (50.5\%) and lineage 5 (15.3\%) for Type 1 and Type 2 PRRSV, respectively, among ORF5-positive farms. In particular, the lineages kor B and C were identified as novel lineages in this study, and lineage kor B comprised only the field viruses isolated from Gyeongnam Province in 2014-2015, establishing regionally unique genetic characteristics. It has also recently been confirmed that commercialized vaccine-like viruses (subgroup C) of Type 1 PRRSV and NADC30-like viruses of Type 2 PRRSV (lineage 1) are spreading rapidly in Korean swine farms. The Korean field viruses were also expected to be antigenically variable as shown in the high diversity of neutralizing epitopes and N-glycosylation sites.

Conclusions: This up-to-date information regarding recent field PRRSVs should be taken into consideration when creating strategies for the application of PRRS control measures, including vaccination in the field.
\end{abstract}

Keywords: Porcine reproductive and respiratory syndrome virus (PRRSV), Genetic diversity, Open reading frame 5 (ORF5) sequence, Phylogenetic analysis

\footnotetext{
* Correspondence: virusmania@korea.kr

${ }^{1}$ Viral Disease Division, Animal and Plant Quarantine Agency, Gimcheon

39660, Republic of Korea

${ }^{4}$ Present address: PRRS research Laboratory, Viral Diseases Division, Animal

and Plant Quarantine Agency, Gimcheon 39660, Republic of Korea

Full list of author information is available at the end of the article
}

(c) The Author(s). 2018 Open Access This article is distributed under the terms of the Creative Commons Attribution 4.0 International License (http://creativecommons.org/licenses/by/4.0/), which permits unrestricted use, distribution, and

reproduction in any medium, provided you give appropriate credit to the original author(s) and the source, provide a link to the Creative Commons license, and indicate if changes were made. The Creative Commons Public Domain Dedication waiver (http://creativecommons.org/publicdomain/zero/1.0/) applies to the data made available in this article, unless otherwise stated. 


\section{Background}

Porcine reproductive and respiratory syndrome virus (PRRSV) is one of the most common and economically significant infectious diseases in the pig industry worldwide [1, 2]. This virus causes clinical disease characterized by reproductive failure in pregnant sows and acute respiratory illness in growing pigs, causing increased preweaning mortality $[3,4]$. PRRSV is a small-enveloped, single-stranded, non-segmented, and positive-sense RNA virus that is a member of the genus Arterivirus in the family Arteriviridae and order Nidovirales [5-7] he PRRSV genome is approximately $15 \mathrm{~kb}$ in size, composed of a $5^{\prime}$ untranslated region (UTR), 10 open reading frames (ORFs), designated ORF1a, ORF1b, ORF2a, ORF2b, and ORF3-7 including ORF5a, and a 3'-UTR [8-11]. ORF1a and ORF1b encode replication-related polymerase proteins that can be autoproteolytically cleaved into at least 16 nonstructural proteins (NSPs) [12-16]. ORFs 2a through 7 encode the following viral structural proteins: six envelope-associated proteins (GP2a, E, GP3, GP4, GP5, and $\mathrm{M}$ ) and the nucleocapsid (N) protein [11, 17-19]. ORF5 encodes the major viral envelope protein GP5. As the most variable structural gene of PRRSV, GP5 plays an important role in viral assembly, infectivity, and the induction of neutralizing antibodies [20-23]. Owing to its high degree of genetic diversity, the ORF5 sequence has been used for diagnostic identification and classification of PRRS field viruses [4, 24-26].

PRRSV is divided into two major genotypes: Type 1 (European type) and Type 2 (North American type) PRRSV. Lelystad and VR2332 are considered reference strains of Type 1 and Type 2 PRRSV, respectively [27]. Type 1 and Type 2 PRRSV exhibit approximately 60\% genomic sequence identity, and $20 \%$ nucleotide sequence variability within each genotype $[28,29]$. Owing to the emergence of highly diverse field viruses, global phylogeny using the ORF5 sequence is characterized by many groups (subtypes 1-4 for Type 1 PRRSV and lineages 1-9 for Type 2 PRRSV) within each of the genotypes, composed of genetically and geographically distinct PRRSVs [30, 31].

Previous studies have also reported the genetic diversity and phylogeny of PRRSVs circulating in the Republic of Korea [32-34]. Type 2 PRRSV has infected swine farms since the mid-1980s [35], while Type 1 PRRSV has spread rapidly since its first detection in 2005 [33]. However, there has been no study regarding the current prevalence and genetic characteristics of PRRSV in PRRS-affected swine farms nationwide. Recent surveys among swine farmers in the Republic of Korea revealed that over $50 \%$ of swine farms have suffered from PRRS, which has been recognized as the most economically important disease in this industry. Combined with the introduction of new modified live vaccines into swine farms over the past three years, the active circulation of field viruses has increased concern regarding the establishment of novel genetic components, and the emergence of antigenic or virulent variants. The following study was conducted to investigate the prevalence, genetic characteristics, and phylogeny of Korean field PRRSVs in recent years (2013-2016).

\section{Methods}

Study design

Clinical samples (lung tissues and sera) submitted to diagnostic labs (Animal and Plant Quarantine Agency and Jeonbuk National University) were collected from pigs (mostly older than 4 weeks old) with poor growth and respiratory illness between 2013 and 2016. All samples were tested by multiplex reverse transcriptionpolymerase chain reaction (RT-PCR) for amplification of ORF7 with primers designed to detect Type 1 and Type 2 PRRSV simultaneously. Virus isolation using ORF7positive samples was attempted in the MARC-145 cell line and porcine alveolar macrophages (PAMs). Selected viral isolates were sequenced for ORF5, and further subjected to genetic analysis and compared with Korean field viruses isolated in 2003-2010, commercial vaccine strains (DV of Porcilis $^{\oplus}$ PRRS, VP-046 of UNISTRAIN ${ }^{\circledR}$ PRRS, Ingelvac PRRS MLV of Ingelvac PRRS ${ }^{\bullet}$ MLV, and P129 of Fostera ${ }^{\circ}$ PRRS) commonly used in the Republic of Korea, PRRSV prototype strains (VR2332 and Lelystad), and field isolates previously reported from other countries.

\section{Sample collection}

A total of 631 clinical samples (lung tissues and sera) were obtained from swine farms located in provinces nationwide: Gyeonggi $(n=107)$, Chungbuk $(n=9)$, Chungnam $(n=27)$, Jeonbuk $(n=69)$, Jeonnam $(n=35)$, Gyeongbuk $(n=61)$, Gyeongnam $(n=307)$, Gangwon $(n=1)$, and Jeju $(n=15)$ in 2013-2016. The lung tissues were homogenized in Dulbecco's minimum essential medium $(20 \% w / v)$ and filtered $(0.45-\mu \mathrm{m}$ filter). The lung homogenates and sera were stored at $-70{ }^{\circ} \mathrm{C}$ until use.

\section{RT-PCR}

Total RNA was extracted from the lung homogenates and sera using the RNeasy mini kit (Qiagen, Hilden, Germany), in accordance with the manufacturer's instructions. To detect and differentiate between Type 1 and Type 2 PRRSV, samples were first subjected to multiplex RT-PCR using genotype-specific ORF7 primers (Table 1) and a OneStep RT-PCR kit (Qiagen), which can simultaneously amplify PCR products of 398 and 433 base pairs (bp) for Type 1 and Type 2 PRRSV, respectively. The ORF7-positive sera were further subjected to RT-PCR for ORF5 amplification. The ORF5 genes of PRRSV were amplified with two pairs of primers 
Table 1 Primer sequences for amplification of ORF5 and ORF7

\begin{tabular}{|c|c|c|c|c|}
\hline \multirow[t]{2}{*}{ Type } & \multicolumn{3}{|l|}{ Primer } & \multirow{2}{*}{$\begin{array}{l}\text { Product } \\
\text { (bp) }\end{array}$} \\
\hline & & Position & Sequence & \\
\hline \multirow[t]{4}{*}{1} & Forward & 14,653-14,671 (ORF7) & 5'-ATGGCCAGCCAGTCAATCA-3' & \multirow[t]{2}{*}{ ORF7 (398) } \\
\hline & Reverse & $15,030-15,050$ (3’NCR) & 5'-TCGCCCTAATTGAATAGGTGA-3' & \\
\hline & Forward & 13,444-13,461 (ORF4) & 5'-AATGAGGTGGGCYACAACC-3' & \multirow[t]{2}{*}{ ORF5 (754) } \\
\hline & Reverse & 15,030-15,050 (ORF6) & 5'-GCGTGACACCTTAAGGGC-3' & \\
\hline \multirow[t]{4}{*}{2} & Forward & 14,933-14,951 (ORF7) & 5'-ATGGCCAGCCAGTCAATCA-3' & \multirow[t]{2}{*}{ ORF7 (433) } \\
\hline & Reverse & $15,346-15,365$ (3’NCR) & 5'-TCGCCCTAATTGAATAGGTGA-3' & \\
\hline & Forward & 13,759-13,778 (ORF4) & 5'-CCATTCTGGTGGCAATTTGA-3' & \multirow[t]{2}{*}{ ORF5 (716) } \\
\hline & Reverse & 14,455-14,474 (ORF6) & 5'-GGCATATATCATCACTGGCG-3' & \\
\hline
\end{tabular}

[33] for Type 1 and Type 2 PRRSV (Table 1), generating PCR products of 754 and $716 \mathrm{bp}$, respectively. The amplification reaction consisted of $2.5 \mu \mathrm{l}$ of $5 \times$ RT-PCR buffer (including $2.5 \mathrm{mM} \mathrm{MgCl} 2$ ), $0.2 \mathrm{mM}$ dNTPs, $0.2 \mu \mathrm{M}$ of each primer, $0.5 \mu \mathrm{l}$ of the enzyme mix, and $5 \mu \mathrm{l}$ of RNA extract in a final volume of $25 \mu \mathrm{l}$. RT-PCR was performed by reverse transcription for $30 \mathrm{~min}$ at $50{ }^{\circ} \mathrm{C}$, termination of reverse transcription for $15 \mathrm{~min}$ at $95{ }^{\circ} \mathrm{C}$, followed by 35 cycles of $20 \mathrm{~s}$ at $94{ }^{\circ} \mathrm{C}, 20 \mathrm{~s}$ at $55^{\circ} \mathrm{C}, 30 \mathrm{~s}$ at $72{ }^{\circ} \mathrm{C}$, and a final extension of $10 \mathrm{~min}$ at $72{ }^{\circ} \mathrm{C}$ in a $\mathrm{C} 1000$ Thermal Cycler (Bio-Rad, Hercules, CA, USA). The RT-PCR amplicons were analyzed using $1 \%$ agarose gel electrophoresis.

\section{Nucleotide (NT) and amino acid (AA) sequences and phylogenetic tree analysis}

Amplified ORF5 products $(n=542)$ were purified using the QIAquick Gel Extraction Kit (Qiagen) and sequenced (Macrogen, Seoul, Korea). Multiple sequence alignment was initially carried out and homology of the NT and AA sequences among the PRRSV isolates was determined with CLC Main Workbench ver. 7.0.3. ORF5 sequences were subjected to analysis of neutralizing epitopes (NEs), putative N-glycosylation sites (Asn-Xaa-Ser/ Thr), and phylogenetic trees compared with those of Korean field viruses $(n=200)$ isolated between 2003 and 2010 , field isolates of foreign countries $(n=109)$, including PRRSV prototype strains (VR2332 and Lelystad), and vaccine strains $(n=4)$ used in the Republic of Korea, available in the GenBank database. The phylogenetic tree was constructed using MEGA6 software with the neighbor-joining method and bootstrap values were calculated on 1000 replicates.

\section{Results}

Prevalence of PRRSVs in the Republic of Korea from 2013 to 2016

Among the 631 clinical samples subjected to ORF7 RTPCR, 38.4\% (242/631) were positive for Type 1 PRRSV, $37.4 \%(236 / 631)$ were positive for Type 2 PRRSV, and 24.2\% (153/631) were positive for both PRRSV genotypes
(Fig. 1). In terms of geographical prevalence by genotype, Type 1 was more prevalent in Gyeonggi and Jeonbuk Provinces, while Type 2 mainly infected in Gyeongbuk Province. Both genotypes were almost equivalently present in the remainder of the provinces.

\section{Phylogenetic analysis and sequence homology}

Phylogenetic analysis based on global PRRSV phylogeny $[30,31]$ indicated that all of the Korean isolates $(n=542)$ from 2003 to 2016 analyzed in this study were classified into pan-European subtype 1 for Type 1 PRRSV, and lineages 1, 4, and 5 and three Korean lineages (lineage kor A, $\mathrm{B}$, and C) for Type 2 PRRSV. Regarding the recent Korean Type 1 field viruses $(n=295)$ isolated in 2013-2016, all of the isolates were classified into subgroups $\mathrm{A}(n=274), \mathrm{B}$ $(n=1)$, and $C(n=20)$ under subtype 1 (Fig. 2a) with infection prevalence rates of $50.5 \%$ (274/542), 0.18\% (1/ $542)$, and 3.69\% (20/542) among ORF5-positive farms, respectively. The recent Korean isolates of subgroup A were grouped with 77 Korean field viruses, two Korean reference strains (E38 and KNU-07) isolated in 2005-2009, and a Spanish strain, CRESA11. One isolate of subgroup B was grouped with four Korean field viruses isolated in 2005-2009, a Thai isolate (03RB1), and 12 European reference strains. Subgroup C was formed with only 20 recent Korean isolates, Lelystad, two vaccine strains (DV and VP-046), and 13 European reference strains. Meanwhile, subtypes 2, 3, and 4 were formed with only Eastern European reference strains. NT (AA) sequence similarity to Lelystad was 84.9-89.8\% (82.2-91.6\%), 85. 9\% (85.6\%), and 93.9-98.4\% (90.1-96.5\%) in subgroups A, B, and C of field viruses isolated in 2013-2016, respectively. Meanwhile, NT (AA) sequence similarity rates to Lelystad were $87.8-90.9 \%$ (86.1-91.6\%) and 85.8-86.9\% (85.2-89.1\%) for subgroups A and B of field viruses isolated in 2005-2009, respectively. In terms of sequence similarity to vaccine strains, NT (AA) sequence similarity to DV was similar to Lelystad for field viruses isolated in 2013-2016 as well as in 2005-2009. NT (AA) sequence similarity to VP-046 was $84.2-88.9 \%$ (81.7-92.6\%), $85.5 \%$ 


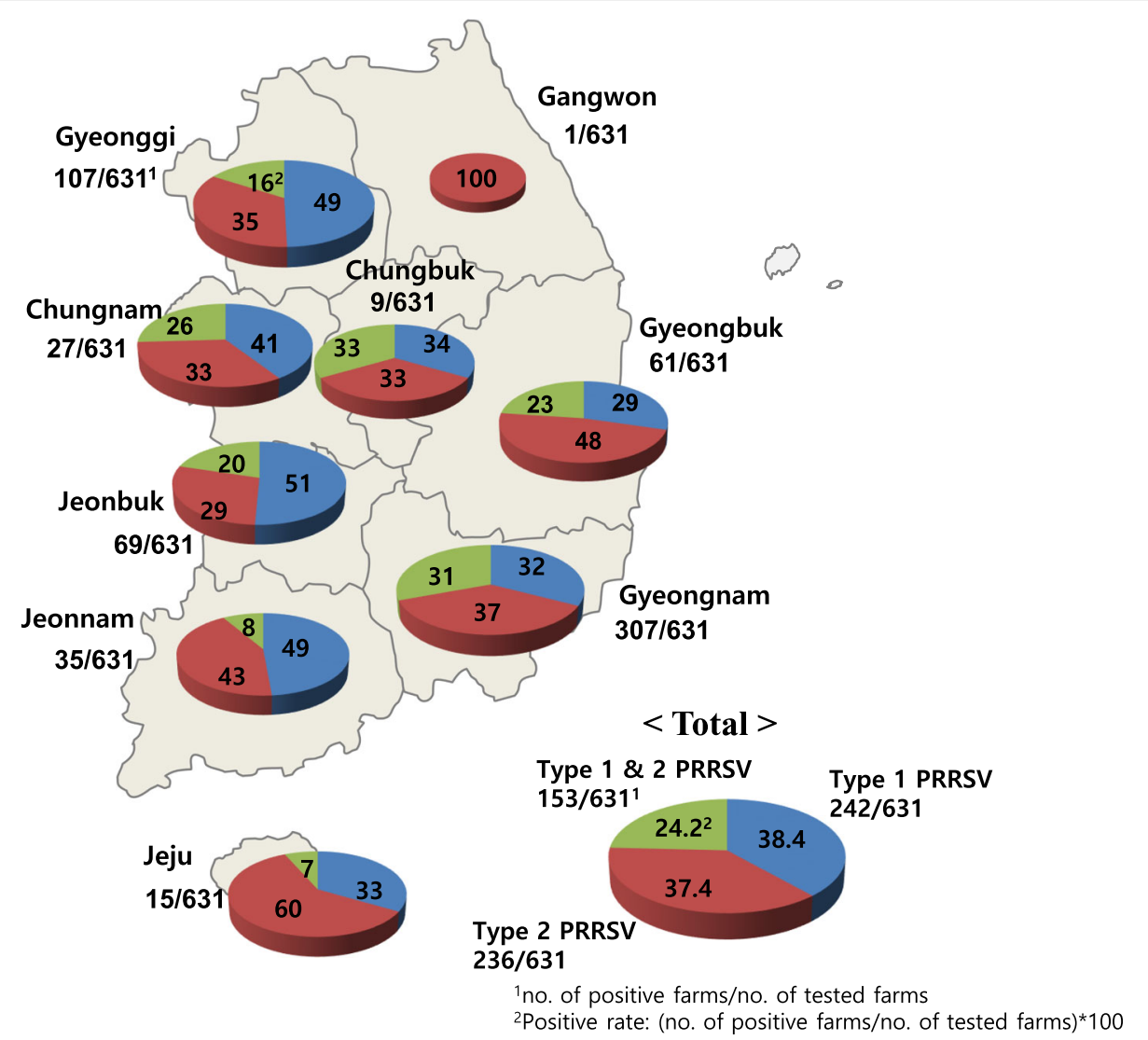

Fig. 1 Geographic distribution of Korean field viruses infected in 631 swine farms with respect to single (Type 1 or Type 2 PRRSV) and co-infection (Type 1 \& 2 PRRSV)

(86.1\%), and 93.7-99.8\% (90.6-99.5\%) in subgroups A, $\mathrm{B}$, and $\mathrm{C}$ of field viruses isolated in 2013-2016, while $86.8-89.8 \%$ (85.6-91.1\%), and $85.5-87.5 \%(85.2-88.6 \%)$ in subgroups A and B of field viruses isolated in 2005-2009, respectively (Table $2 \mathrm{~A}$ ).

The Korean Type 2 field viruses $(n=247)$ isolated in 2013-2016 were classified into five different lineages: lineage $1(n=9)$, lineage $5(n=83)$, lineage kor A $(n=33)$, lineage kor $\mathrm{B}(n=72)$, and lineage kor $\mathrm{C}(n=50)$ (Fig. $2 \mathrm{~b})$, with infection prevalence rates of $1.66 \%$ (9/542), $15.3 \%$ (83/542), 6.08\% (33/542), 13.2\% (72/542), and 9.22\% (50/ 542) among ORF5-positive farms, respectively. The recent isolates of lineage 1 were grouped with highly virulent viruses of the United States (NADC30 virus, MN184, etc.) and China (Fig. 1c). The recent isolates of lineage 5 were grouped with 57 Korean viruses, three Korean reference strains (CA-1, PL97-1, and LMY) isolated in 2005-2009 [36], and VR2332, Ingelvac PRRS MLV, and so on. Meanwhile, three Korean lineages (kor A, B, and C) formed their own group separate from PRRSVs isolated from foreign countries. Importantly, lineage kor B was grouped only with recent field viruses isolated in 2014-2016, while lineages kor A and C included 24 and 32 field viruses isolated in 2003-2010, respectively [32, 36]. NT (AA) sequence similarity rates to VR2332 were $82.3-86.9 \%$ (81.7-87.6\%), $87.6-99.3 \%$ (85.6-99.0\%), $85.1-89.1 \%$ (82.1-87.6\%), 85.7-89.1\% (83.6-90.1\%), and $85.2-86.4 \%$ (83.6-86.1\%) for lineages 1 and 5 and lineages kor A, B, and $C$ of field viruses isolated in 2013-2016, respectively. Meanwhile, NT (AA) sequence similarity rates to VR2332 were $88.9 \%$ (88.1\%), 88.9-99.5\% (88.1-99.0\%), 87.6-89.6\% (82.6-88.6\%), and 84.7-87.1\% (84.1-88.6\%) for lineages 4 and 5 and kor $\mathrm{A}$ and $\mathrm{C}$ of field viruses isolated in 2003-2010, respectively. Regarding sequence similarity to vaccine strains, NT (AA) sequence similarity to Ingelvac PRRS MLV was highly similar to VR2332 for field viruses isolated in 2013-2016 as well as in 2003-2010. NT (AA) sequence similarity to P129 was $85.2-86.6 \%$ (84.6-86.6\%), $\quad 86.7-91.7 \% \quad(84.6-91.5 \%), \quad 85.6-89.2 \%$ (85.1-90.1\%), 86.1-89.1\% (85.1-89.1\%), and $82.6-86.9 \%$ (81.6-87.6\%) in lineages 1 and 5 and kor A, B, and C of field viruses isolated in 2013-2016, while 89.7\% (89.1\%), 88.2-91.9\% (88.1-92.5\%), 87.2-90.2\% (86.1-93.0\%), and 85.4-88.1\% (84.1-89.1\%) in lineages 4 and 5 and kor A and $C$ of field viruses isolated in 2003-2010, respectively (Table 2B). 


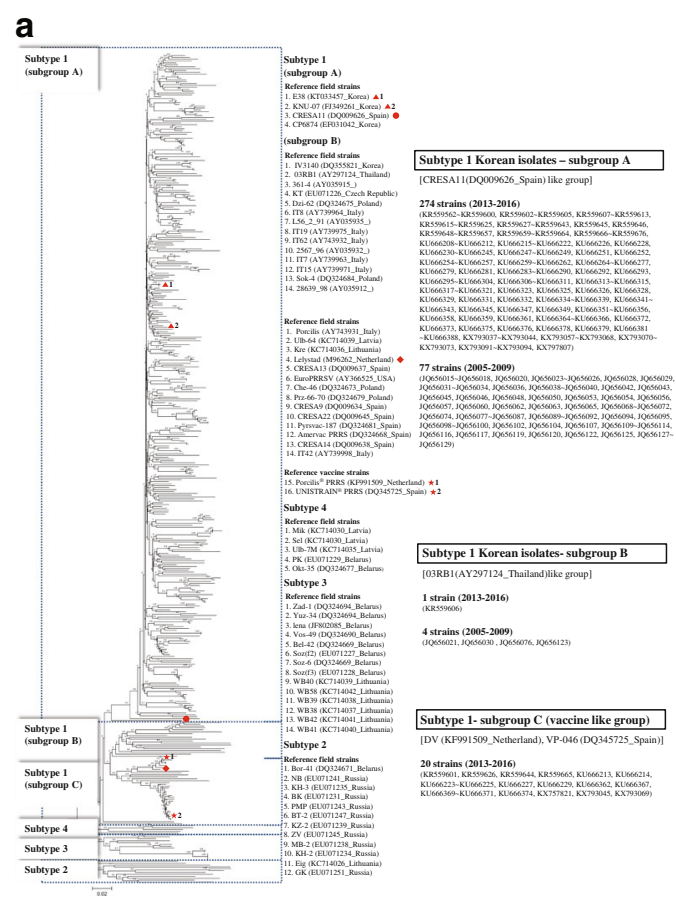

b

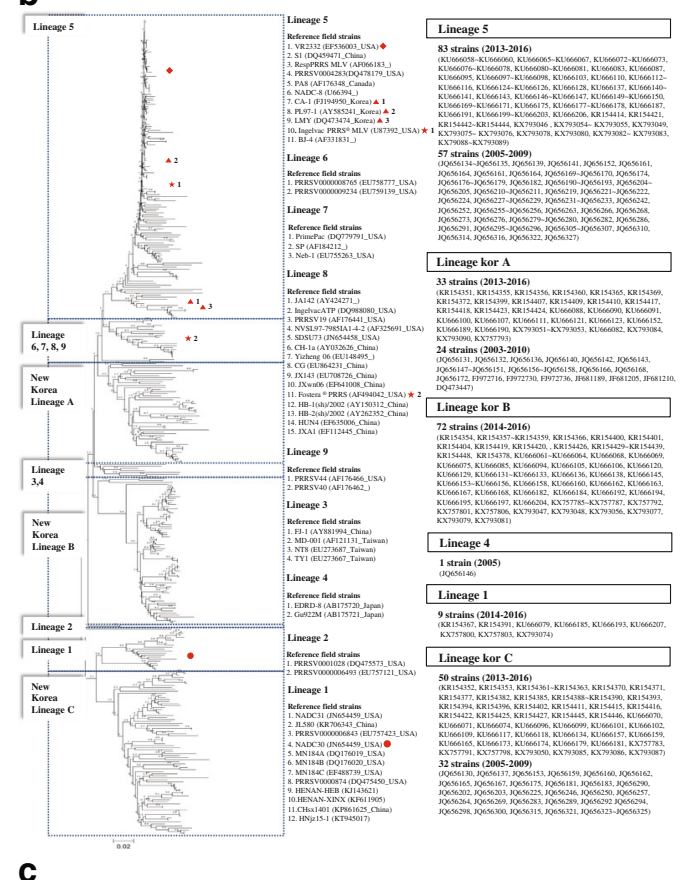

C

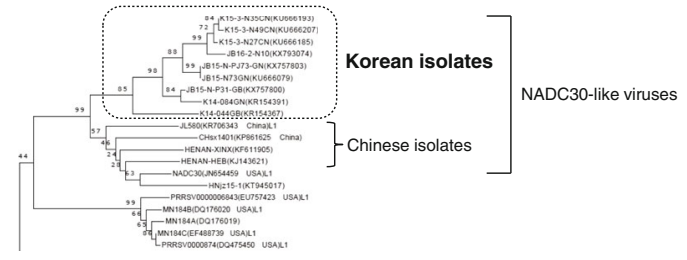

Fig. 2 Phylogenetic analysis using ORF5 nucleotide sequences of Type 1 (a) and Type 2 PRRS (b) field isolates obtained from this study and the GenBank database. The tree was constructed by maximum-likelihood method and the grouping was referred from the previous studies [30, $31,56]$. Prototype viruses of each type, vaccine viruses used in Korean swine farms and Korean reference strains were marked with $\bullet$ $\star$ and

$\boldsymbol{\Delta}$, respectively. CRESA11 was marked with $\bullet$. A group of NADC30-like viruses was magnified in (c)

\section{NEs and N-glycosylation sites of ORF5 amino acid sequences}

NT sequence deletions or additions in the ORF5 sequence were not observed in the Korean isolates. Korean Type 1 PRRSV showed 7 and 25 different AA sequences of NEs (residues 29-35) [23] for field viruses isolated in 2005-2009 and 2013-2016, respectively. For Type 2 PRRSV, 12 and 23 different AA sequences in NEs (residues 37-45) [37] were observed for Korean field viruses isolated in 2003-2010 and 2013-2016, respectively. NEs (WSFADGN for DV or Lelystad, WSFVDGN for VP046, SHLQLIYNL for Ingelvac PRRS MLV, or VR2332 and SHFQLIYNL for P129) of vaccine or PRRSV prototype strains (VR2332 and Lelystad) were compared with those of field isolates (Table 3). NEs of vaccine or PRRSV prototype strains were observed in 91.4\% (74/81) and $80.0 \%(236 / 295)$ of Type 1 PRRSV field isolates of 2005-2009 and 2013-2016, and 67.5\% (77/114) and 61.1\% (151/247) of Type 2 PRRSV field isolates of 2003-2010 and 2013-2016, respectively. The NE (WSFADGN) of DV or Lelystad appeared as a main epitope in subgroups A, B, and $C$ for all Korean Type 1 PRRS isolates, while the NE (SHLQLIYNL) of Ingelvac PRRS MLV or VR2332 was observed as the primary epitope of all Type 2 PRRSV lineages except for kor A and B of field isolates of 2013-2016, in which the NE (SHFQLIYNL) of P129 was the primary epitope. Regarding the pattern of $\mathrm{N}$-glycosylation (number and sites of $\mathrm{N}$-glycosylation), putative $\mathrm{N}$-glycosylation sites were found at residues 37, 46, and 53 among the majority of Type 1 PRRS field isolates, resulting in 37-46-53 as the main N-glycosylation pattern throughout all subgroups in 2005-2016. In contrast, even if the putative N-glycosylation sites were highly conserved at residues 44 and 51 for Type 2 PRRS field isolates, the $\mathrm{N}$-glycosylation pattern was significantly variable regardless of isolation year and lineage: 4-5 sites (residues 30, 33, 34, 44, 51, and 59) for lineage 1 , 3-5 sites (residues 30, 32-35, 43, 44, 50, and 51) for lineage 5, 2-4 sites (residues 32-35, 44, and 51) for lineage kor A, 2-4 sites (residues 32-35, 43, 44, 50, and 51) for lineage kor B, and 2-5 sites (residues 30, 32-35, 44, and 51) for lineage kor $\mathrm{C}$. Although the $\mathrm{N}$-glycosylation pattern of Ingelvac PRRS MLV (30-33-44-51) was identified as the main pattern in lineages 1 and 5 of field viruses isolated in 2003-2010, novel N-glycosylation patterns appeared highly dominant overall. The N-glycosylation pattern (34-44-51) 
Table 2 ORF5 nucleotide (NT) and amino acid (AA) sequence similarity of subtype 1/subgroups of type 1 PRRSV (A) and lineages of type 2 PRRSV (B) to prototypes/vaccine strains

\begin{tabular}{|c|c|c|c|c|c|}
\hline \multirow[t]{3}{*}{ Type } & \multirow[t]{3}{*}{ Isolated year } & \multirow[t]{3}{*}{ Subtype /Lineage } & \multicolumn{3}{|l|}{ Sequence similarity } \\
\hline & & & prototype & Vaccine strain & \\
\hline & & & Lelystad virus & DV (Porcilis ${ }^{\circledast}$ PRRS) & VP-046 (UNISTRAIN PRRS) \\
\hline \multicolumn{6}{|l|}{ (A) } \\
\hline \multirow[t]{5}{*}{1} & \multirow[t]{2}{*}{ 2005-2009 } & subtype 1-A & $87.8-90.9(86.1-91.6)^{a}$ & 87.6-91.1 (86.1-91.6) & 86.8-89.8 (85.6-91.1) \\
\hline & & subtype 1-B & $85.8-86.9(85.2-89.1)$ & $85.3-86.8(84.2-88.1)$ & $85.5-87.5(85.2-88.6)$ \\
\hline & \multirow[t]{3}{*}{ 2013-2016 } & subtype 1-A & 84.9-89.8 (82.2-91.6) & $85.0-89.6(82.2-90.6)$ & $84.2-88.9(81.7-92.6)$ \\
\hline & & subtype 1-B & $86.0(85.6)$ & $85.5(84.7)$ & $85.5(86.1)$ \\
\hline & & subtype $1-C$ & 93.9-98.4 (90.1-96.5) & $93-4-99.5$ (89.6-98.5) & $93.7-99.8(90.6-99.5)$ \\
\hline \multirow[t]{3}{*}{ Type } & \multirow[t]{3}{*}{ Isolated year } & \multirow[t]{3}{*}{ Subtype /Lineage } & \multicolumn{3}{|l|}{ Sequence similarity } \\
\hline & & & prototype & \multicolumn{2}{|l|}{ Vaccine strain } \\
\hline & & & VR2332 & Ingelvac PRRS MLV (Ingelvac ${ }^{\oplus}$ PRRS MLV) & P129 (Fostera ${ }^{\oplus}$ PRRS) \\
\hline \multicolumn{6}{|l|}{ (B) } \\
\hline \multirow[t]{9}{*}{2} & \multirow[t]{4}{*}{$2003-2010$} & lineage 4 & $88.9(88.1)^{b}$ & 88.9 (88.6) & $89.7(89.1)$ \\
\hline & & lineage 5 & 88.9-99.5 (88.1-99.0) & 89.9-99.8 (87.6-99.5) & $88.2-91.9(88.1-92.5)$ \\
\hline & & lineage kor A & 87.6-89.6 (82.6-88.6) & 86.7-89.7 (84.1-91.5) & 87.2-90.2 (86.1-93.0) \\
\hline & & lineage kor $C$ & $84.7-87.1$ (84.1-88.6) & $84.7-87.1(83.6-88.1)$ & $85.4-88.1(84.1-89.1)$ \\
\hline & \multirow[t]{5}{*}{ 2013-2016 } & lineage 1 & $82.3-86.9(81.7-87.6)$ & $84.9-86.1$ (83.1-85.6) & $85.2-86.6(84.6-86.6)$ \\
\hline & & lineage 5 & 87.6-99.3 (85.6-99.0) & 87.9-99.7 (87.1-99.5) & $86.7-91.7(84.6-91.5)$ \\
\hline & & lineage kor A & $85.1-89.1$ (82.1-87.6) & $85.4-88.7(82.6-88.1)$ & 85.6-89.2 (85.1-90.1) \\
\hline & & lineage kor B & $85.7-89.1(83.6-90.1)$ & 85.7-89.1 (83.1-89.6) & $86.1-89.1(85.1-89.1)$ \\
\hline & & lineage kor $C$ & $85.2-86.4(83.6-86.1)$ & $83.6-87.6(81.2-87.1)$ & $82.6-86.9(81.6-87.6)$ \\
\hline
\end{tabular}

${ }^{a}$ NT and AA sequence similarity to Type 1 PRRSV prototypes (Lelystad) and vaccine strains (DV and VP-046). Parenthesis indicates AA sequence similarity ${ }^{b}$ NT and AA sequence similarity to Type 2 PRRSV prototypes (VR2332) and vaccine strains (Ingelvac PRRS MLV, P129). Parenthesis indicates AA sequence similarity

of VR2332 was identified in all lineages of Korean field viruses isolated in 2003-2016, while the N-glycosylation pattern (46-53) of Lelystad was not identified in all field isolates. Many of the AA changes were observed in hypervariable regions of Korean Type 1 (residues 99-106) and Type 2 (residues 32-39 and 57-61) field viruses isolated in 2013-2016 (Fig. 3).

\section{Discussion}

In this study, the recent geographic prevalence and genetic characteristics of Korean PRRSVs were investigated using field isolates circulating in swine farms nationwide. RT-PCR of 631 clinical samples (farms) revealed that 38. $4 \%(242 / 631)$ were infected by Type 1 PRRSV, $37.4 \%$ (236/631) were infected by Type 2 PRRSV, and $24.2 \%$ (153/631) were simultaneously infected by both Type 1 and Type 2 PRRSV. When compared with a previous report [38], in which the single infection rates of Type 1 or Type 2 PRRSV and co-infection of both types in swine farms were 29.4, 54.4, and $16.2 \%$, respectively, it was noted that Type 1 PRRSV has become highly prevalent in the 10 years following its first isolation in 2005. In addition, the increased number of farms infected with both Type 1 and Type 2 PRRSV suggested that effective control against PRRS in the Republic of Korea might have to be implemented with the use of control measures against both genotypes.

All of the Korean Type 1 PRRS viruses were classified into the subgroups $\mathrm{A}, \mathrm{B}$, and $\mathrm{C}$ of subtype 1 , consistent with a previous report [34]. The majority of the Korean Type 1 PRRS isolates (274 isolates from 2013 to 2016 and 77 isolates from 2005 to 2009) belonged to subgroup A, showing close relatedness with a Spanish strain, CRESA11. Subgroup B viruses (one isolate from 2013 to 2016 and four isolates from 2005 to 2009) were grouped with a Thai strain (03RB1) and pan-European strains. Subgroup C viruses (20 isolates from 2013 to 2016) were grouped with Type 1 PRRS live vaccine strains (DV and VP-046) and other pan-European strains. Lee et al. [39] first reported that a Korean isolate was grouped with DV. However, it is not possible to define genetic relatedness between the field isolate and the vaccine strain due to the lack of sequence information. Subgroup C viruses (5 DV- and 15 VP-046-like strains) isolated in this study showed a phylogenetic closeness to the vaccine strains with greater than $99 \%$ NT sequence similarity without geographical predominance. Therefore, it has been suggested that the vaccine- 
Table 3 Diverse neutralizing epitopes and putative N-glycosylation sties on GP5 of Korean field PRRSVs isolated in 2003-2016 and commercial vaccine strains

\begin{tabular}{|c|c|c|c|c|}
\hline Type & $\begin{array}{l}\text { Vaccine } \\
\text { strain/ } \\
\text { Isolated year }\end{array}$ & $\begin{array}{l}\text { Subgroup } \\
\text { /Lineage }\end{array}$ & AA sequence of neutralizing epitopes & AA position for putative $\mathrm{N}$-glycosylation sites \\
\hline \multirow[t]{7}{*}{1} & DV & $\begin{array}{l}\text { subgroup } \\
\mathrm{C}\end{array}$ & WSFADGN & $37-46-53$ \\
\hline & VP-046 & $\begin{array}{l}\text { subgroup } \\
\text { A }\end{array}$ & WSFVDGN & $35-46-53$ \\
\hline & \multirow[t]{2}{*}{ 2005-2009 } & $\begin{array}{l}\text { subgroup } \\
\text { A }\end{array}$ & $\frac{\text { WSFADGN(71) }}{\text { WSFADCN(1) }}$, WSFVDGN(1), WSFADGS(3), WSFASGN(1), & $37-46-53(75), 37-53(2)$ \\
\hline & & $\begin{array}{l}\text { subgroup } \\
\text { B }\end{array}$ & 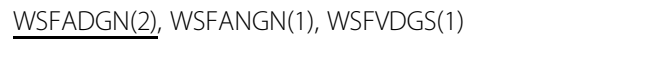 & $37-46-53(3), 37-53(1)$ \\
\hline & \multirow[t]{3}{*}{ 2013-2016 } & $\begin{array}{l}\text { subgroup } \\
\text { A }\end{array}$ & $\begin{array}{l}\text { WSFADGN(214), WSFAYGN(1), WSFVDGN(5), } \\
\text { WSFADGT(7), WSFADGS(11), WSSADGR(1), WSFADGK(2), } \\
\text { WSFANGN(1), WSFADGD(2), WSSADGS(3), WPFADGN(4), } \\
\text { WSSADGN(5), CSFAAGS(4), WSSADGE(1), WSFADGA(1), } \\
\text { WSFADAN(1), WPFAAGS(3), WSFAGGN(2), WSFAEGN(1), } \\
\text { WSSANGS(1), LSFVDCN(1), WPFAEGN(1), YSSANGN(1), } \\
\text { LSYADGS(1) }\end{array}$ & $\begin{array}{l}37-46-53(252), 37-53(12), 35-46-53(2), 33-37-46-53(1) \\
\begin{array}{l}37-46-53-61(2), \\
(1)\end{array}\end{array}$ \\
\hline & & $\begin{array}{l}\text { subgroup } \\
\text { B }\end{array}$ & $\underline{\text { WSFANGN(1) }}$ & $\underline{37-46-53(1)}$ \\
\hline & & subgroup & 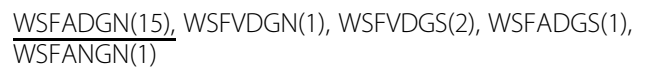 & $37-46-53(14), 35-46-53(4), 37-53(2)$ \\
\hline \multirow[t]{11}{*}{2} & $\begin{array}{l}\text { IngelvacPRRS } \\
\text { MLV }\end{array}$ & lineage 5 & SHLQLIYNL & $30-33-44-51$ \\
\hline & P129 & lineage 8 & SHFQLIYNL & $32-44-51$ \\
\hline & \multirow[t]{4}{*}{ 2003-2010 } & lineage 4 & SHLQLIYNL & $30-33-44-51$ \\
\hline & & lineage 5 & $\begin{array}{l}\text { SHLQLIYNL(43), SNLQLIYNL(11), SKFQLIYNL(1), } \\
\text { XNLQLIYNL(1), SNLQSIYNL(1) }\end{array}$ & $\begin{array}{l}30-33-44-51(17), 34-44-51(17), 32-33-44-51(7), 33-34-44- \\
51(3), 32-44-51(2), 30-35-44-51(1), 30-33-43-50(1), 30-33- \\
34-44-51(4), 30-34-44-51(3), 30-34-35-44-51(1), 33-44- \\
51(1)\end{array}$ \\
\hline & & $\begin{array}{l}\text { lineage } \\
\text { kor A }\end{array}$ & $\begin{array}{l}\text { SHFQLIYNL(9), SHLQLIYNL(1), SKFQLIYNL(1), SKIQLIYNL(2), } \\
\text { SHIQLIYNL(1), SKLQSIYKL(1), SNLQLIYNL(2), SNFQLIYNL(4), } \\
\text { SKLQLIYNL(3) }\end{array}$ & $\begin{array}{l}\frac{32-44-51(5)}{50(1), 35-43-50(1), 33-43-50(3), 30-33-44-51(1), 34-44-} \\
51(2), 33-34-44-51(1), 30-35-44-51(1)\end{array}$ \\
\hline & & $\begin{array}{l}\text { lineage } \\
\text { kor } C\end{array}$ & $\underline{\text { SHLQLIYNL(24), SHLQSIYNL(8) }}$ & $\begin{array}{l}\frac{30-34-44-51(13),}{3} 34-44-51(3), 30-44-51(1), 30-33-44-51(2), \\
51(2)\end{array}$ \\
\hline & \multirow[t]{5}{*}{ 2013-2016 } & lineage 1 & $\underline{\text { SHLQLIYNL(9) }}$ & $\frac{30-33-34-44-51(4)}{44-51(1), 30-33-44-51(1)}$ \\
\hline & & lineage 5 & 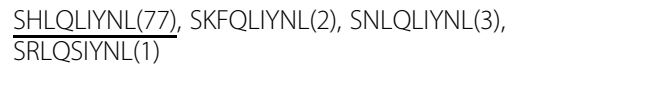 & $\begin{array}{l}30-33-44-51(48), 32-35-44-51(1), 33-34-44-51(4), 30-33-34- \\
44-51(10), 34-44-51(7), 30-33-43-50(2), 30-44-51(2), 30-35- \\
44-51(4), 32-33-44-51(3), 33-44-51(2)\end{array}$ \\
\hline & & $\begin{array}{l}\text { lineage } \\
\text { kor A }\end{array}$ & $\begin{array}{l}\text { SHFQLIYNL(14), SHLQLIYNL(2), SKFQLIYNL(2), } \\
\text { SNLQLIYNL(1), SYSQLIYNL(4), SYSQSIYDL(1), } \\
\text { SYSQSIYNL(1), SKLQLIYNL(4), SKLQLIYNM(1), } \\
\text { SNFQLIYNL(2), SHIQLIYNL(1) }\end{array}$ & $\begin{array}{l}\frac{34-44-51(17)}{35-44-51(2), 33-44-51(3), 32-34-44-51(1), 32-51 \text { (1) }}\end{array}$ \\
\hline & & $\begin{array}{l}\text { lineage } \\
\text { kor B }\end{array}$ & $\begin{array}{l}\text { SNLQLIYNL(47), SHLQLIYNL(2), STLQLIYNL(12), } \\
\text { STSQLIYNL(1), SKLQLIYNL(7), SNPQLIYNL(1), } \\
\text { SKLQLIYDL(1),SHLQSIYNL(1) }\end{array}$ & $\begin{array}{l}\text { 34-44-51(39), 34-43-50(2), 34-35-44-51(6), 33-44-51(4), 34- } \\
51(1), 33-44-51(1), 32-44-51(8), 33-43-50(1), 33-34-44- \\
51(9), 32-33-44-51(1)\end{array}$ \\
\hline & & $\begin{array}{l}\text { lineage } \\
\text { kor } C\end{array}$ & $\begin{array}{l}\text { SHLQLIYNL(38), SHLQLIYKM(1), SHLQSIYNL(4), } \\
\text { SHSQLIYNL(1), SHFQSIYNL(1), SHLQLIYDL(1), } \\
\text { SQLQLIYNL(3), SHLQLIYKL(1) }\end{array}$ & $\begin{array}{l}30-33-44-51(8), 30-35-44-51(6), 34-44-51(5), 30-34-44-51 \\
(4), 32-35-44-51(1), 32-33-44-51(2), 33-51(1), 30-34-35-44- \\
51(4), 33-34-44-51(2), 35-51(1), 34-35-44-51(3), 33-44-51 \\
(6), 30-33-51(1), 30-33-34-44-51(5), 35-44-51(1)\end{array}$ \\
\hline
\end{tabular}




\section{a}
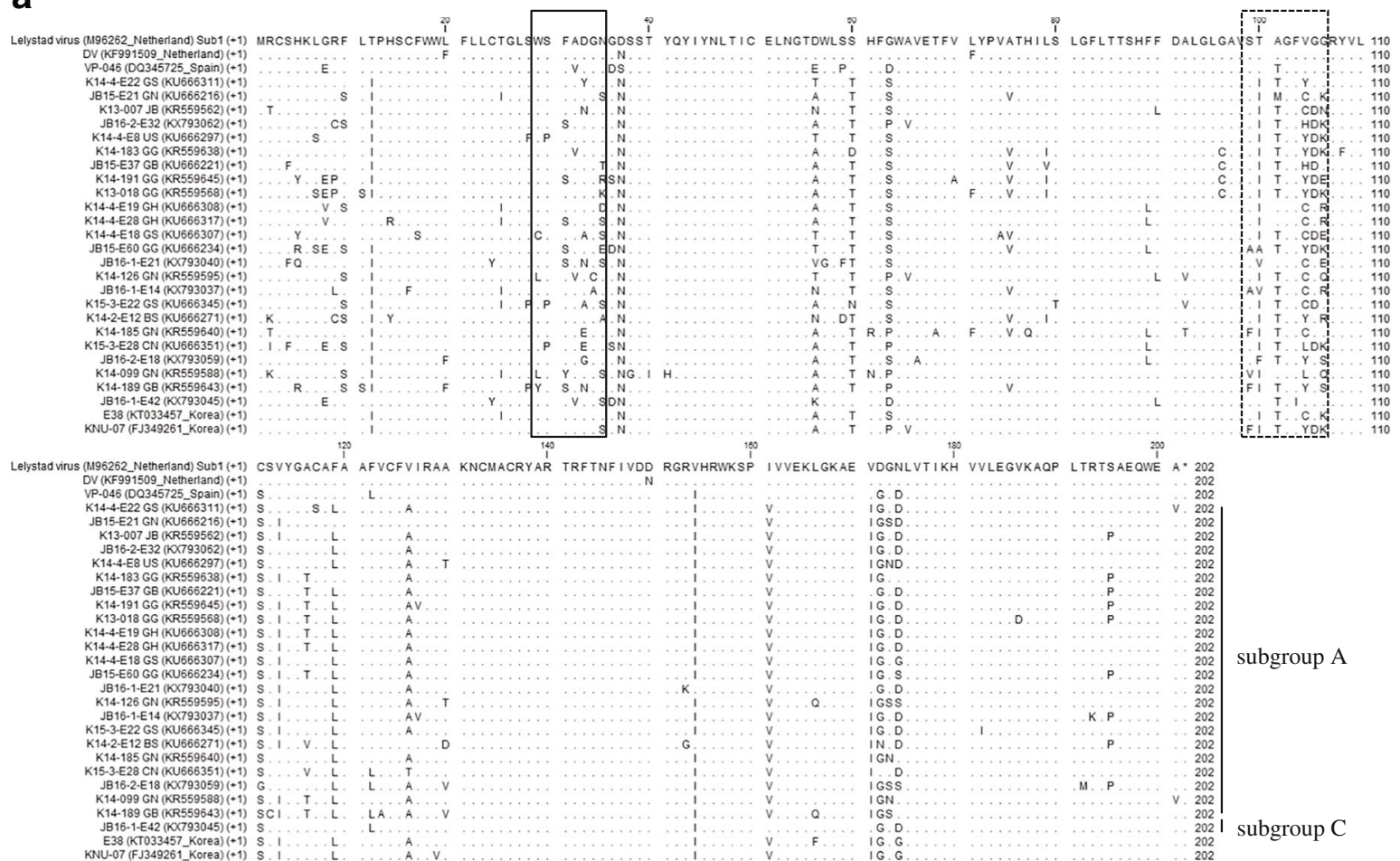

b
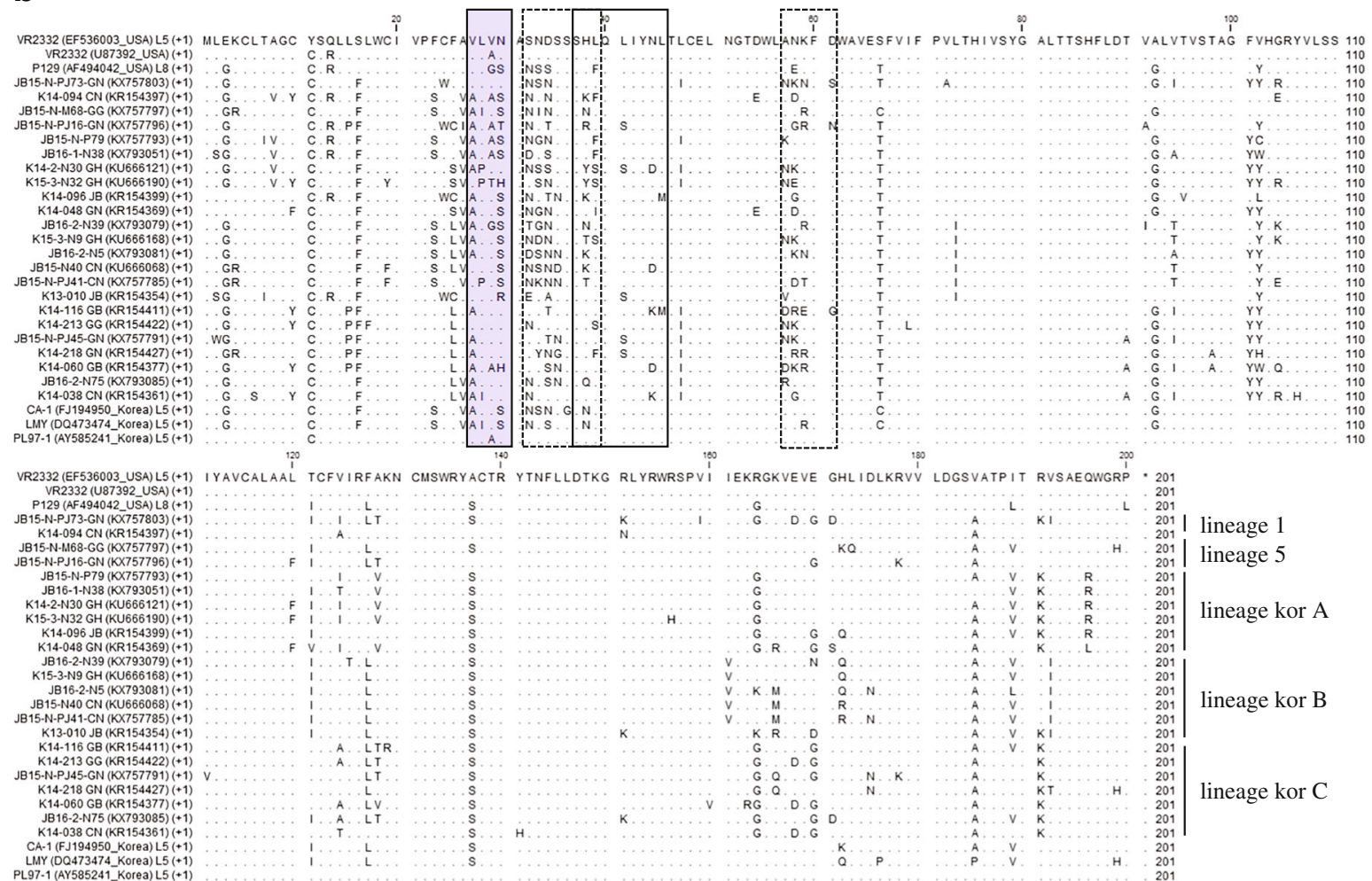

Fig. 3 (See legend on next page.) 
(See figure on previous page.)

Fig. 3 Multiple alignment of ORF5 amino acid sequences of representative isolates in each subgroup (Type 1 PRRSV) (a) and lineage (Type 2 PRRSV (b). The representative isolates were selected based on main amino acid sequence of neutralizing epitope of Type 1 PRRSV (residues 29-35) [23] and Type 2 PRRSV (residues 37-45) [37]. The solid line box and gray color box represent neutralizing epitope and decoy epiotpe (residues 27-31) [57], respectively. The dot-line box indicates hypervariable regions [58]

like viruses originated from the Type 1 PRRS live vaccines commercialized in 2014 and would become highly prevalent over time in the Republic of Korea.

Korean Type 2 PRRS viruses have been divided into lineages 1,4 , and 5 , as well as the Korean lineages kor A, B, and C based on global PRRSV phylogeny [30]. The majority of the Korean Type 2 PRRS field isolates belonged to lineage 5 and the Korean lineages. Lineage 5 viruses were grouped with VR2332-like viruses genetically close to the Ingelvac PRRS MLV vaccine virus, which has been used commercially since 1996. The lineage also included Korean reference field strains, PL97-1 [40], LMY [32, 33], and CA-1 [41]. Regarding the emergence of novel Korean lineages, lineages kor $\mathrm{B}$ and $\mathrm{C}$ were first classified in this study, while lineage kor A was first reported as a Korean lineage in a previous study of field isolates of 2010 [36]. Lineages kor A and C were observed to include field viruses isolated in 20052009 and 2013-2016, which indicated that these groups have developed genetic components geographically distinct from those in foreign countries for longer than 10 years. Meanwhile, lineage kor B comprised only recent isolates that originated from Gyeongnam Province between 2014 and 2016, suggesting that this group may have recently established regionally unique genetic properties within the Republic of Korea.

Nine viruses of lineage 1 isolated between 2014 and 2015 were closely related to NADC30, with 92.3-94.9\% NT sequence similarity to NADC30, which was one of the representative virulent strains along with MN184 and SDSU73 in the United States [42]. Chinese NADC30-like viruses (HNjz15, JL580, HENAN-HEB, HENAN-XINX, and CHsx140) were also reported to cause obvious clinical symptoms in pigs with virulence comparable to that of NADC30 [43-45]. It should be noted that the circulation of NADC30-like viruses in the Republic of Korea has not been previously reported. Although the virulence of NADC30-like viruses is known to be less than that of highly pathogenic PRRS viruses [43], there is a strong need to define the virulence of recent NADC30-like isolates in pigs in Korean farms. There are two possible explanations for the recent emergence of NADC30-like viruses. First, the NADC30like viruses may have recently been introduced by the importation of breeding pigs, likely as Chinese NADC30-like viruses [45]. Second, it has been assumed that NADC30 was introduced 7-10 years ago, circulated in a particular environment (e.g., with wild boars as hosts) based on an estimated mutational change rate $(0.78 \%$ per year) of ORF5 NTs identified in previous studies [24, 46], and was recently transmitted to domestic swine farms in various ways (e.g., wild boar farming).

The NEs and N-glycosylation patterns of GP5 were highly variable, and novel epitopes and $\mathrm{N}$-glycosylation patterns continuously emerged and disappeared in the field viruses, although this was more apparent in field viruses isolated in 2013-2016 than in 2003-2010 (Table 3). As expected, NEs of vaccine strains or PRRSV prototype strains existed in the majority of field isolates (82.2 and $61.0 \%$ for Type 1 and Type 2 PRRSV, respectively) without a preference for a certain subgroup or lineage. In particular, NEs of DV (or Lelystad) (WSFADGN) and Ingelvac PRRS MLV (or VR2332) (SHLQLIYNL) were maintained in approximately 80.4 and $54.6 \%$ of field isolates, respectively. It has been speculated that the dominance of the two NEs might be due to extensive vaccination using vaccine strains (Ingelvac PRRS MLV and DV) that originated from PRRSV prototype strains. Nevertheless, it has been noted that the emergence of novel NEs has been significantly expedited over time in PRRSV field isolates (8.6\% of 2005-2009 field isolates vs. $20.3 \%$ of $2013-2016$ field isolates for Type 1 PRRSV; $31.8 \%$ of $2005-2009$ field isolates vs. $42.3 \%$ of 2013-2016 field isolates for Type 2 PRRSV). Regarding the $\mathrm{N}$-glycosylation pattern, it was interesting to note that $\mathrm{N}$-glycosylation sites were highly diverse and changeable in Korean Type 2 PRRS field isolates, while being conserved in Korean Type 1 PRRS field isolates. NEs and the Nglycosylation pattern are closely associated with virus propagation, neutralization, and immunological protection [47-51]. Therefore, it has been suggested that the strong preference for mutation of NEs and the N-glycosylation pattern, particularly in Type 2 PRRSV, might be associated with limited protective efficacy of PRRS vaccination against heterologous viruses in the field, as shown in previous studies [52-54].

Type 2 vaccine-like viruses have become highly prevalent since the first use of Ingelvac PRRS MLV in 1996 [32]. In this study, lineage 5 , including the Type 2 vaccine strain and vaccine-like viruses, showed the highest prevalence $(15.3 \%)$ in the field. Likewise, the recent prevalence of subgroup $C$, including Type 1 vaccine-like viruses, is low (3.69\%). However, extensive use of Type 1 live vaccines may result in a dramatically increased prevalence of Type 1 vaccine-like viruses and/or isolation of field viruses sharing a genomic part of Type 1 live 
vaccine strains in the near future, caused by genetic evolution mechanisms of PRRSV, random point mutations, and homologous recombination [55]. To minimize the circulation of live vaccine strains in the field, we may have to strengthen swine farm bio-security to prevent contamination of live vaccine strains among swine farms vaccinated with live vaccines. At the same time, limited use of live vaccines may be recommended in young pigs (3-8 weeks old) or pregnant gilts/sows of PRRS-affected farms.

\section{Conclusions}

This study suggests that PRRS viruses in the Republic of Korea have recently developed genetic characteristics geographically distinct from currently prevalent global PRRS viruses or commercial vaccine strains. Therefore, further study will be required to evaluate how the established genetic characteristics have affected PRRS outbreaks in domestic swine farms, which will provide important information for the implementation of control and preventive measures in swine farms.

\section{Abbreviations}

AA: Amino Acid; NE: Neutralizing epitope; NT: Nucleotide; ORF: Open Reading Frame; PRRSV: Porcine reproductive and respiratory syndrome virus

\section{Acknowledgements}

We would like to thank our funding sources.

\section{Funding}

This work was funded by grant (project no.: QIA I-1541780-2012-14-03) from the Animal and Plant Quarantine Agency (APQA), Ministry of Agriculture, Food and Rural Affairs, Republic of Korea as well as by grant (313005-3 and 315029-3) from the Technology Development Program for Bio-industry, Ministry of Food, Agriculture, Forestry and Fisheries, Republic of Korea.

\section{Availability of data and materials}

All data were included in the manuscript as tables and figures. The phylogenetic data was deposited in the TreeBase at http://purl.org/phylo/ treebase/phylows/study/TB2:S22357? x-accesscode=706d5d6a5a4a320ed 3e6cf4d81c8d02f\&format=html. The study ID on Treebase is S22357.

\section{Authors' contributions}

HJK, JEY and JES conducted the experiments and produced data. ARK, WIK, CHL, JL, ISC and SEC provided field samples and worked for analysis of the data. CSH designed and supervised the study. HJK and CSH wrote the manuscript. All authors contributed to the final editing and approval of the manuscript.

\section{Ethics approval and consent to participate}

This article does not contain any studies with animals performed by any of the authors.

\section{Competing interests}

The authors declare that they have no competing interests.

\section{Publisher's Note}

Springer Nature remains neutral with regard to jurisdictional claims in published maps and institutional affiliations.

\section{Author details}

'Viral Disease Division, Animal and Plant Quarantine Agency, Gimcheon 39660, Republic of Korea. ${ }^{2}$ Animal Virology Laboratory, School of Life Sciences, Kyungpook National University, Daegu 41566, Republic of Korea. ${ }^{3}$ College of Veterinary Medicine, Jeonbuk National University, Iksan 54596,
Republic of Korea. ${ }^{4}$ Present address: PRRS research Laboratory, Viral Diseases Division, Animal and Plant Quarantine Agency, Gimcheon 39660, Republic of Korea.

Received: 29 May 2017 Accepted: 30 April 2018

Published online: 16 May 2018

\section{References}

1. Holtkamp DJ, Kliebenstein JB, Neumann E, Zimmerman JJ, Rotto H, Yoder TK, Wang C, Yeske P, Mowrer CL, Haley CA. Assessment of the economic impact of porcine reproductive and respiratory syndrome virus on United States pork producers. J Swine Health Prod. 2013;21 (2):72.

2. Neumann EJ, Kliebenstein JB, Johnson CD, Mabry JW, Bush EJ, Seitzinger AH, Green AL, Zimmerman JJ. Assessment of the economic impact of porcine reproductive and respiratory syndrome on swine production in the United States. J Am Vet Med Assoc. 2005;227(3): 385-92.

3. Keffaber K. Reproductive failure of unknown aetiology. AASP Newslett. 1989:1:1-10.

4. Andreyev VG, Wesley RD, Mengeling WL, Vorwald AC, Lager KM. Genetic variation and phylogenetic relationships of 22 porcine reproductive and respiratory syndrome virus (PRRSV) field strains based on sequence analysis of open reading frame 5. Arch Virol. 1997;142(5):993-1001.

5. Cavanagh D. Nidovirales: a new order comprising Coronaviridae and Arteriviridae. Arch Virol. 1997;142(3):629-33.

6. Fauquet CM, Mayo MA, Maniloff J, Desselberger U, Ball LA. Virus taxonomy classification and nomenclature of viruses. In: Fauquet CM, Mayo MA, Maniloff J, Desselberger U, Ball LA, editors. 8th ICTV report of the international committee on taxonomy of viruses. London: Elsevier/Academic Press; 2005. p. 1259

7. Spaan WJM, Brian D, Cavanagh D, de Groot RJ, Enjuanes L, Gorbalenya AE, Holmes KV, Masters PS, Rottier PJ, Taguchi F, Talbot P. Family coronaviridae. In: Fauquet CM, Mayo MA, Maniloff J, Desselberg U, Ball LA, editors. Virus taxonomy: eighth report of the international committee on taxonomy of viruses. London: Elsevier Academic Press; 2005. p. 947-64.

8. Firth AE, Zevenhoven-Dobbe JC, Wills NM, Go YY, Balasuriya UB, Atkins JF, Snijder EJ, Posthuma CC. Discovery of a small arterivirus gene that overlaps the GP5 coding sequence and is important for virus production. J. Gen. Virol. 2011;92(Pt 5):1097-106.

9. Johnson CR, Griggs TF, Gnanandarajah J, Murtaugh MP. Novel structural protein in porcine reproductive and respiratory syndrome virus encoded by an alternative ORF5 present in all arteriviruses. J Gen Virol. 2011;92(Pt 5):1107-16.

10. Snijder EJ, Meulenberg JJ. The molecular biology of arteriviruses. J. Gen. Virol. 1998;79(Pt 5):961-79.

11. Wu WH, Fang Y, Farwell R, Steffen-Bien M, Rowland RR, ChristopherHennings J, Nelson EA. A 10-kDa structural protein of porcine reproductive and respiratory syndrome virus encoded by ORF $2 \mathrm{~b}$. Virology. 2001;287(1):183-91.

12. Bautista EM, Faaberg KS, Mickelson D, McGruder ED. Functional properties of the predicted helicase of porcine reproductive and respiratory syndrome virus. Virology. 2002;298(2):258-70.

13. Fang Y, Snijder EJ. The PRRSV replicase: exploring the multifunctionality of an intriguing set of nonstructural proteins. Virus Res. 2010;154(1-2):61-76.

14. Fang $Y$, Treffers EE, Li $Y$, Tas $A$, Sun $Z$, van der Meer $Y$, de Ru AH, van Veelen PA, Atkins JF, Snijder EJ, Firth AE. Efficient -2 frameshifting by mammalian ribosomes to synthesize an additional arterivirus protein. Proc Natl Acad Sci U S A. 2012;109(43):E2920-8.

15. Snijder EJ, Spaan WJM. Arteriviruses In Knipe DM, Howley PM, Griffin DE, Lamb RA, Martin MA, Roizman B and Straus SE (eds). Fields virology, $5^{\text {th }}$ ed. Philadelphia: Lippincott Williams and Wilkins Publishers; 2007. pp.1337-1355.

16. van Aken D, Zevenhoven-Dobbe J, Gorbalenya AE, Snijder EJ. Proteolytic maturation of replicase polyprotein ppla by the nsp4 main proteinase is essential for equine arteritis virus replication and includes internal cleavage of nsp7. J Gen Virol. 2006;87(Pt 12):3473-82.

17. Doan DN, Dokland T. Structure of the nucleocapsid protein of porcine reproductive and respiratory syndrome virus. Structure. 2003;11(11):1445-51.

18. Meulenberg JJ, van Nieuwstadt AP, van Essen-Zandbergen A, Bos-de Ruijter $J N$, Langeveld JP, Meloen RH. Localization and fine mapping of antigenic sites on the nucleocapsid protein $\mathrm{N}$ of porcine reproductive and respiratory syndrome virus with monoclonal antibodies. Virology. 1998;252(1):106-14. 
19. Wootton S, Yoo D, Rogan D. Full-length sequence of a Canadian porcine reproductive and respiratory syndrome virus (PRRSV) isolate. Arch Virol. 2000;145(11):2297-323.

20. Dea S, Gagnon CA, Mardassi H, Pirzadeh B, Rogan D. Current knowledge on the structural proteins of porcine reproductive and respiratory syndrome (PRRS) virus: comparison of the north American and European isolates. Arch Virol. 2000;145(4):659-88.

21. Pirzadeh B, Gagnon CA, Dea S. Genomic and antigenic variations of porcine reproductive and respiratory syndrome virus major envelope GP5 glycoprotein. Can J Vet Res. 1998;62(3):170-7.

22. Wissink EH, Kroese MV, van Wijk HA, Rijsewijk FA, Meulenberg JJ, Rottier PJ. Envelope protein requirements for the assembly of infectious virions of porcine reproductive and respiratory syndrome virus. J Virol. 2005;79(19):12495-506.

23. Wissink EH, van Wijk HA, Kroese MV, Weiland E, Meulenberg JJ, Rottier PJ, van Rijn PA. The major envelope protein, GP5, of a European porcine reproductive and respiratory syndrome virus contains a neutralization epitope in its N-terminal ectodomain. J. Gen. Virol. 2003;84(Pt 6):1535-43.

24. Cha SH, Chang CC, Yoon KJ. Instability of the restriction fragment length polymorphism pattern of open reading frame 5 of porcine reproductive and respiratory syndrome virus during sequential pig-to-pig passages. J Clin Microbiol. 2004;42(10):4462-7.

25. Dee, S.A., Torremorell, M., Rossow, K., Mahlum, C., Otake, S., Faaberg, K., 2001. Identification of genetically diverse sequences (ORF 5) of porcine reproductive and respiratory syndrome virus in a swine herd. Can.J.Vet.Res. 65(4), 254-260

26. Kapur V, Elam MR, Pawlovich TM, Murtaugh MP. Genetic variation in porcine reproductive and respiratory syndrome virus isolates in the midwestern United States. J. Gen. Virol. 1996;77(Pt 6):1271-6.

27. Kuhn JH, Lauck M, Bailey AL, Shchetinin AM, Vishnevskaya TV, Bao Y, Ng TF, LeBreton M, Schneider BS, Gillis A, Tamoufe U, Diffo Jle D, Takuo JM, Kondov NO, Coffey LL, Wolfe ND, Delwart E, Clawson AN, Postnikova E, Bollinger L, Lackemeyer MG, Radoshitzky SR, Palacios G, Wada J, Shevtsova ZV, Jahrling PB, Lapin BA, Deriabin PG, Dunowska M, Alkhovsky SV, Rogers J, Friedrich TC, O'Connor DH, Goldberg TL. Reorganization and expansion of the nidoviral family Arteriviridae. Arch Virol. 2016;161(3):755-68.

28. Kim WI, Yoon KJ. Molecular assessment of the role of envelope-associated structural proteins in cross neutralization among different PRRS viruses. Virus Genes. 2008;37(3):380-91.

29. Meng XJ. Heterogeneity of porcine reproductive and respiratory syndrome virus: implications for current vaccine efficacy and future vaccine development. Vet Microbiol. 2000;74(4):309-29.

30. Shi M, Lam TT, Hon CC, Hui RK, Faaberg KS, Wennblom T, Murtaugh MP, Stadejek T, Leung FC. Molecular epidemiology of PRRSV: a phylogenetic perspective. Virus Res. 2010;154(1-2):7-17.

31. Shi M, Lam TT, Hon CC, Murtaugh MP, Davies PR, Hui RK, Li J, Wong LT, Yip CW, Jiang JW, Leung FC. Phylogeny-based evolutionary, demographical, and geographical dissection of north American type 2 porcine reproductive and respiratory syndrome viruses. J Virol. 2010;84(17):8700-11.

32. Cha SH, Choi EJ, Park JH, Yoon SR, Song JY, Kwon JH, Song HJ, Yoon KJ. Molecular characterization of recent Korean porcine reproductive and respiratory syndrome (PRRS) viruses and comparison to other Asian PRRS viruses. Vet Microbiol. 2006;117(2-4):248-57.

33. Choi EJ, Lee CH, Song JY, Song HJ, Park CK, Kim B, Shin YK. Genetic diversity of porcine reproductive and respiratory syndrome virus in Korea. J Vet Sci. 2013;14(2):115-24.

34. Kim SH, Roh IS, Choi EJ, Lee C, Lee CH, Lee KH, Lee KK, Song YK, Lee OS, Park CK. A molecular analysis of European porcine reproductive and respiratory syndrome virus isolated in South Korea. Vet Microbiol. 2010; 143(2-4):394-400.

35. Shin J-H, Kang Y-B, Kim Y-J, et al. Sero-epidemiological studies on porcine reproductive and respiratorysyndrome in Korea. I. Detection of indirect fluorescent antibodies. RDA J Agri Sci. 1993;35:572-6.

36. Kim HK, Nguyen VG, Kim IO, Park JH, Park SJ, Rho SM, Han JY, Park BK. Epidemiologic and phylogenetic characteristics of porcine reproductive and respiratory syndrome viruses in conventional swine farms of Jeju Island as a candidate region for PRRSV eradication. Transbound Emerg Dis. 2012;59(1):62-71.

37. Larochelle R, D'Allaire S, Magar R. Molecular epidemiology of porcine reproductive and respiratory syndrome virus (PRRSV) in Quebec. Virus Res. 2003;96:3-14.

38. Lee C, Kim H, Kang B, Yeom M, Han S, Moon H, Park S, Kim H, Song D, Park B. Prevalence and phylogenetic analysis of the isolated type I porcine reproductive and respiratory syndrome virus from 2007 to 2008 in Korea. Virus Genes. 2010;40(2):225-30.

39. Lee JA, Lee NH, Lee JB, Park SY, Song CS, Choi IS, Lee SW. Genetic diversity of the Korean field strains of porcine reproductive and respiratory syndrome virus. Infect Genet Evol. 2016;40:288-94.

40. Kang SY, Yun SI, Park HS, Park CK, Choi HS, Lee YM. Molecular characterization of PL97-1, the first Korean isolate of the porcine reproductive and respiratory syndrome virus. Virus Res. 2004;104(2):165-79.

41. Koo HN, Oh JM, Lee JK, Choi JY, Lee KS, Roh JY, Je YH, Jin BR, Yoo SS, Kim JS, Kim YI, Yoon IJ, Woo SD. Molecular characterization of ORFs 2 to 7 of Korean porcine reproductive and respiratory syndrome virus (CA) and its protein expression by recombinant baculoviruses. J Microbiol. 2008;46(6):709-19.

42. Brockmeier SL, Loving CL, Vorwald AC, Kehrli ME Jr, Baker RB, Nicholson TL, Lager KM, Miller LC, Faaberg KS. Genomic sequence and virulence comparison of four type 2 porcine reproductive and respiratory syndrome virus strains. Virus Res. 2012;169(1):212-21.

43. Sun Z, Wang J, Bai X, Ji G, Yan H, Li Y, Wang Y, Tan F, Xiao Y, Li X, Tian K. Pathogenicity comparison between highly pathogenic and NADC30-like porcine reproductive and respiratory syndrome virus. Arch Virol. 2016;161(8):2257-61.

44. Zhao K, Ye C, Chang XB, Jiang CG, Wang SJ, Cai XH, Tong GZ, Tian ZJ, Sh $\mathrm{M}, \mathrm{An} \mathrm{TQ}$. Importation and recombination are responsible for the latest emergence of highly pathogenic porcine reproductive and respiratory syndrome virus in China. J Virol. 2015;89(20):10712-6.

45. Zhou L, Wang Z, Ding Y, Ge X, Guo X, Yang H. NADC30-like strain of porcine reproductive and respiratory syndrome virus. China Emerg infect Dis. 2015;21(12):2256-7.

46. Chang CC, Yoon KJ, Zimmerman JJ, Harmon KM, Dixon PM, Dvorak CM, Murtaugh MP. Evolution of porcine reproductive and respiratory syndrome virus during sequential passages in pigs. J Virol. 2002;76(10):4750-63.

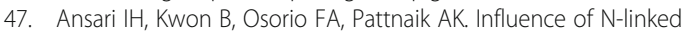
glycosylation of porcine reproductive and respiratory syndrome virus GP5 on virus infectivity, antigenicity, and ability to induce neutralizing antibodies. J Virol. 2006;80(8):3994-4004.

48. Das PB, Vu HL, Dinh PX, Cooney JL, Kwon B, Osorio FA, Pattnaik AK. Glycosylation of minor envelope glycoproteins of porcine reproductive and respiratory syndrome virus in infectious virus recovery, receptor interaction, and immune response. Virology. 2011;410(2):385-94.

49. Delputte $\mathrm{PL}$, Nauwynck HJ. Porcine arterivirus infection of alveolar macrophages is mediated by sialic acid on the virus. J Virol. 2004;78(15):8094-101.

50. Faaberg KS, Hocker JD, Erdman MM, Harris DL, Nelson EA, Torremorell M, Plagemann PG. Neutralizing antibody responses of pigs infected with natural GP5 N-glycan mutants of porcine reproductive and respiratory syndrome virus. Viral Immunol. 2006;19(2):294-304.

51. Li J, Tao S, Orlando R, Murtaugh MP. N-glycosylation profiling of porcine reproductive and respiratory syndrome virus envelope glycoprotein 5 . Virology. 2015;478:86-98.

52. $\mathrm{Hu}$ J, Zhang C. Porcine reproductive and respiratory syndrome virus vaccines: current status and strategies to a universal vaccine. Transbound EmergDis. 2014;61(2):109-20.

53. Kim T, Park C, Choi K, Jeong J, Kang I, Park SJ, Chae C. Comparison of two commercial type 1 porcine reproductive and respiratory syndrome virus (PRRSV) modified live vaccines against heterologous type 1 and type 2 PRRSV challenge in growing pigs. Clin Vaccine Immunol. 2015;22(6):631-40.

54. Labarque G, Reeth KV, Nauwynck H, Drexler C, Van Gucht S, Pensaert M. Impact of genetic diversity of European-type porcine reproductive and respiratory syndrome virus strains on vaccine efficacy. Vaccine. 2004;22(31-32):4183-90.

55. Liu D, Zhou R, Zhang J, Zhou L, Jiang Q, Guo X, Ge X, Yang $H$. Recombination analyses between two strains of porcine reproductive and respiratory syndrome virus in vivo. Virus Res. 2010;155:473-86.

56. Stadejek T, Oleksiewicz MB, Scherbakov AV, Timina AM, Krabbe JS, Chabros K, Potapchuk D. Definition of subtypes in the European genotype of porcine reproductive and respiratory syndrome virus : nucleocapsid characteristics and geographical distribution in Europe. Arch Virol. 2008;153:1479-88.

57. Ostrowski M, Galeota JA, Jar AM, Platt KB, Osorio FA, Lopez OJ. Identification of neutralizing and nonneutralizing epitopes in the porcine reproductive and respiratory syndrome virus GP5 ectodomain. J Virol. 2002;76:4241-50.

58. Key KF, Hagshenas G, Guenette DK, Swenson SL, Toth TE, Meng XJ. Genetic variation and phylogenetic analyses the ORF5 gene of acute porcine reproductive and respiratory syndrome virus isolates. Vet Microbiol. 2001;83:249-63. 